\title{
Managing Corporate Events and Job Satisfaction Among Young Professionals
}

UDK: 005.551:06.06(497.11) ; 005-053.81:331.101.32
DOI: 10.7595/management.fon.2013.0002

\begin{abstract}
This paper focuses on young, highly educated professionals, at the beginning or in the early career stages. The subject of the research is the analysis of the potential use of corporate events as an organizational mechanism for managing job satisfaction among young professionals in Serbia. Literature review shows that corporate events are primarily considered as a marketing mechanism. Management aspects are dominantly included in the area of operational organization of these events, while their role as a mechanism of organizational integration and the achievement of important organizational goals in the domain of managing certain categories of employees, is neglected by large. The aim of this research is to review the current state, draw conclusions and hypothesize on the potential use of corporate events as a tool for managing job satisfaction among young professionals. The work is based on empirical research. The results show that, within the investigated sample, corporate events with the purpose of organizational integration dominate over events of learning nature. The results also show that this is contrary to the expectations of the respondents, who report a preference towards events through which they can improve individual skills for performing job-related tasks, enable job enrichment and/or enlargement, and improve qualifications for more complicated tasks. The results also show that corporate events are insufficiently used for the purpose of promoting the work of young professionals, and do not support processes of individual and organizational learning.
\end{abstract}

Keywords: Corporate events, Job satisfaction, Young professionals

\section{Introduction}

This paper explores the topic of using corporate events as a mechanism of managing young highly educated professionals as a specific category of employees. Literature review shows that corporate events are regarded primarily and used predominantly as a marketing mechanism. Management aspects are dominantly considered in the area of operational organization of these events, while their role as a mechanism of organizational integration and the achievement of important organizational goals in the domain of managing certain categories of employees are largely neglected. Our study focuses on the analysis of the potential use of corporate events as an organizational mechanism for managing job satisfaction among young professionals in Serbia. Thus we want to redirect the attention of the academic and professional community from the dominant attitude of regarding corporate events as organizational events aimed at customers' attraction and retention, introduction and promotion of new products or services, to the attitude that affirms corporate events as a mechanism of managing employees' behavior; the mechanism that is in the hands of the company's management and that can successfully be used for a different approach in managing specific categories of employees. Since the relevant literature does not either describe or analyze the link between corporate events and human resources of the organization to a significant extent, our study is set up as an exploratory empirical study, with an aim to empirically explore this relationship, draw conclusions and hypothesize about the potential use of corporate events for the management of job satisfaction among young professionals. Accordingly, the first part is smaller in scope; it sets the basic theoretical and conceptual el-

1 Faculty of Economics, University of Belgrade, anaa@ekof.bg.ac.rs

2 Faculty of Economics, University of Belgrade, marinap@ekof.bg.ac.rs 
ements of the research and formulates the framework of the research, while the second part contains empirical investigation, presentation of the main results, conclusions and the implications of the research for management theory and practice.

\section{Theoretical and Research Framework}

The term "corporate events" is used to refer to a wide range of different organizational events. The International Dictionary of Event Management (2001) defines corporate events as events that the company (organization) sponsors to achieve a specific goal, such as animation of buyers, introduction and promotion of new products or services, providing incentives and training for employees, but also other activities. In the field of business administration, event management has traditionally been regarded as an issue of corporate marketing (Kostic-Stankovic et al, 2012), rather than that of organization and management. In the field of management and organization special attention was paid to corporate events that were linked to the concept of corporate culture and the needs of managers to use corporate events to manage corporate culture (Deal, Kennedy, 1982). In the contemporary literature and practice, managing corporate events is becoming more and more of central interest, and is researched not only in terms of its relevance to the behavior of people in organizations, but also to the organizational aspects of the performance and economics of organization (Bowdin et al., 2006; Goldblat, 2002; Smith et al., 1994).

On the other hand, job satisfaction is one of the most commonly researched concepts in the field of organization and management. Job satisfaction is a complex psychological category that includes cognitive, affective and evaluative reactions of an employee to the job (Spector, 1997). This means that job satisfaction includes certain assumptions and values of employees (cognitive aspect), feelings that employees have for certain elements (components) of the job performed (affective aspect) and, finally, evaluation of the job (evaluative aspect). Job satisfaction is also a complex business category, since it includes several elements, i.e. components such as satisfaction with workplace, satisfaction with supervisor, satisfaction with colleagues and others. Job satisfaction is related to the employees' system of values; research shows that, the more the outcomes are highly valued by employees, the higher the satisfaction (Vroom, 1964). From the perspective of organizational behavior, job satisfaction is one of the most important aspects of individual behavior in the organization and is brought into connection with the employees' level of motivation to work, with their productivity, the level of absenteeism from work, as well as the fluctuation of the employees (Thierry, Koopman-Iwema, 1984). Employees' motivation and job satisfaction are so tightly interrelated that many well-known theories of motivation were categorized as theories of job satisfaction (e.g. theories of Maslow hierarchy of needs and Herzberg's two-factor theory, in Locke, 1976). Studies show a significant correlation between the employees' level of job satisfaction and their willingness to act in a benevolent, constructive and collegial way (in accordance with the concept of the organization as a good citizen - organizational citizenship behavior). For managers and owners, perhaps the most important thing is to consider the effects that job satisfaction has on individual and organizational performance. Knowledge in this domain is still contradictory, since research confirms a weak correlation between job satisfaction and employees' individual performance, and shows that there are results on how the two influence each other, as well as that individual performances affect the level of job satisfaction among employees (Robbins, 2003).

However, literature review shows that there are no studies that directly connect management of job satisfaction of young professionals and corporate events as related organizational categories. This question is particularly interesting when placed in the specific business milieu of Serbia. On the basis of our knowledge about managing the category of young, highly educated professionals, the employees within this structure possess strongly expressed needs for achievement and personal development, highly expressed individualism and, commonly, difficulties with integration into a group, in terms of identification (and especially subordination ) of their individual goals to the goals of an organization as a whole (Hamori et al, 2012; London, 1993; Whitely et al, 1991; London et al, 1984). The motivational profile of this category of employees shows that internal aspects of motivation are often more important than the external ones. In this population, job satisfaction is one of the most important motivational mechanisms. On the other hand, the employees in this category, with their knowledge and skills, are an important element of the organizational knowledge base, but also an important development potential of the organization, whose behavior and orientation influence the realization of the strategic goals of the organization, its development and the ability to successfully survive in the market. Therefore, it is very important for an organization to study carefully and appropriately the incentive mechanisms of this category of employees, and adapt them to their motivational profiles as much 
as possible. In this study, we look at corporate events as an organizational tool for managing young professionals, in order to derive both theoretical and practical implications for managing this specific category of employees. This connection has not been clearly observed or studied in relevant literature so far, and it is our intention to open this new perspective.

\section{Research}

Given the lack of theoretical and empirical papers on this topic, our research was designed with the aim to review the situation, draw some conclusions and hypothesize about the potentials of using corporate events for the management of job satisfaction among young professionals.

Taking into account the population of interest for our study, we used a sample of master and PhD students of Economics at Belgrade University who are employed at the same time. The choice of a sample was primarily determined by the need to focus the research clearly on the category of young professionals - people with university education, work experience and ambition to continue professional development through academic education at master academic or doctoral studies. The respondents were mainly employed in the following positions: financial analysis expert, market analysis expert, financial analyst, teaching assistant, risk manager, credit analyst, procurement manager, marketing director, finance director, head of recruitment and selection in human resources and the like.

The survey was conducted in the years 2011 and 2012 and it included the two successive generations of students. These students were sent an online survey at their email addresses. For online-questionnaire design and data collection of the respondents we used a free software available on the Internet at the website www.google.rs. The response rate to the online survey was 0.32 . We examined the job satisfaction scale using Spector's job satisfaction instrument (Spector, 1997). According to Spector, the overall job satisfaction consists of the following composite factors: pay, promotion, supervision, fringe benefits, contingent rewards, operating procedures, nature of work, coworkers, communication. Each composite factor consists of four variables, presented in the questionnaire through the questions.

The collected data were further analyzed in SPSS statistical software. While analyzing the data, we used descriptive measures to explain the structure of the sample, as well as the outline of the answers to the key questions. Due to the nature of the data, these were predominantly percentages. To draw conclusions about the independence between the demographic characteristics of respondents and key points related to job satisfaction, we used chi-square test.

The structure of the respondents shows that both men and women were represented equally. Dominantly represented are the respondents who have at least tertiary education, aged 24 to 34, single and without children (Table 1).

Table 1: Respondents - Structure

\begin{tabular}{|l|l|l|}
\hline Variable & Modality & percentage \\
\hline \multirow{4}{*}{ Sex } & Male & 51,1 \\
\cline { 2 - 3 } & female & 48,9 \\
\hline \multirow{4}{*}{ marital status } & To age 24 & 2,2 \\
\cline { 2 - 3 } & 25 to 34 & 86,7 \\
\cline { 2 - 3 } & 35 to 44 & 11,1 \\
\hline \multirow{3}{*}{ children } & single & 62,2 \\
\cline { 2 - 3 } & married & 37,8 \\
\hline \multirow{4}{*}{ education } & no children & 71,1 \\
\cline { 2 - 3 } & have children & 28,9 \\
\hline & university degree & 28,9 \\
\cline { 2 - 3 } & master of arts degree & 40 \\
\cline { 2 - 3 } & master & 28,9 \\
\cline { 2 - 3 } & academic specialization & 2,2 \\
\hline
\end{tabular}


In the field of organizational characteristics, we considered the type of ownership of the organization in which the respondent is employed, the business that the organization deals in, the age and the size of the organization.

We placed two groups of corporate events into the focus of the research: (1) corporate events with a learning function, and (2) corporate events with an integration function.

Corporate events with integration function include celebrations and gatherings within an organization on the occasions of general interest and importance (New Year's Day, company celebrations), then important events in the employees' lives (getting married, child birth, the defense of master's, specialist, etc. paper, but also the unfortunate events, when the support of work environment is preferred, as well as the important events for the company (receiving certificates and awards). In this category, we also classified introducing new employees to other members of the organization. The essential feature of these events is the need to use an event as an occasion to celebrate and socialize, to meet the employees' needs for belonging and socialization - in a word, for integration within an organization.

Corporate Events with learning function include different types of education and training of employees - corporate seminars in which only some employees participate, (for example. training sales people) or all of them; then, trainings in the workplace or elsewhere, as well as the presentation of new products in the company assortments. The events aimed at team building are relevant to both groups of corporate events, because they are to be achieved as the goals of learning and integration, and this is how we treated them.

All corporate events were researched from two perspectives - in terms of their presence in/absence from the organization where the respondent works, as well as in terms of the respondent's affective reactions to a nonexisting event that the respondent would like to be included into organization's events portfolio. In this way, the participants mapped the presence/absence of the categories of corporate events in question, as well as their affinities to the inclusion of new categories of corporate events in organizational practice.

\section{Results of the Research}

The results of the research will be presented with regard to the composite factors that measure job satisfaction (Table 2), and then we will present the distribution of certain corporate events within the respondents' organizations, as well as their reported needs (desires) for the existence of certain corporate events.

\subsection{Job satisfaction}

Nature of work. Among the factors of job satisfaction researched, job itself occupies the top position for the young professionals. Our respondents report that they are satisfied with the very nature of their job, that their job makes sense, that they are proud of their job, that they love it and enjoy doing it.

Supervision. Superior's attitude to employees is an important constituent factor of job satisfaction. In our research, young professionals ranked it at a high position: 2 . The respondents report their satisfaction with the superior's competence in business, with fair treatment of the employees by the superior, and they even express certain emotional reactions to the superior with a positive answer to the question: "I love my superior". The respondents do not report that they notice the superior's lack of interest for employees' feelings.

Coworkers. The respondents report satisfaction with their co-workers and even express certain emotional reactions to them with a positive answer to the question: "I love my colleague". They do not report the consequences of incompetent colleagues' behavior, or conflicts in the workplace.

Communication. The respondents report a neutral attitude towards the quality of communication within an organization and towards being informed about events in the company. The objectives of organizations in which they work are clear to them, as well as the tasks they perform. There are significant differences in the responses depending on the marital status of the respondents. Namely, taking into account the influence of this personal characteristic of the respondents, we come to the conclusion that marital status affects employees' satisfaction with communication in the workplace. To be more precise, the respondents qualified 
as married report dissatisfaction with communication in workplace, while single respondents report satisfaction with communication in workplace.

Work conditions. The respondents report a considerable load of work at their workplace (the result with the highest single value), but do not report being overloaded by too much administration, by regulations and procedures at work, or with the bureaucratization of tasks and processes. Also, respondents do not have the feeling that their initiatives are deliberately blocked.

Pay. The respondents report satisfaction with the amount of money they receive and with a salary as an indicator of their position in the organization; at the same time, they report dissatisfaction with the frequency and the amount of a raise and the prospects for the increase in salary.

Fringe benefits. Although they report satisfaction with the benefits they receive, the respondents state that there are benefits that they are supposed to, but do not receive. In terms of external and internal fairness of their benefits, they report a neutral attitude. They feel a slight disappointment when thinking about whether their results are rewarded as they should be.

Table 2. Ranking composite factors of job satisfaction

\begin{tabular}{|c|l|}
\hline Rank & \multicolumn{1}{|c|}{ Construct } \\
\hline 1 & Job nature \\
\hline 2 & Superiors \\
\hline 3 & Colleagues \\
\hline 4 & Communication within an organization \\
\hline 5 & Recognition of work \\
\hline 6 & Work conditions \\
\hline 7 & Salary \\
\hline 8 & Work promotion \\
\hline 9 & Financial and/or non-financial benefits \\
\hline
\end{tabular}

\subsection{Corporate events}

The analysis of corporate events in the respondents' organizations shows that events with an integration function are more common in relation to corporate events with a learning function (Table 3).

As the most common event in organizations, our respondents report New Year's Eve (86\% of the respondents). Gatherings of the employees on the important events in their lives in order to celebrate with colleagues are also highly represented. It is surprising to find that celebrations of the Day of the company are presented below the average (46\%), and it is very indicative that the important events for the company are not represented at all (eg. winning prizes at fairs - only 18\%), introducing new members and team building events (also only $18 \%$ ). These are also the events that respondents would most like to have in their organizations $43 \%$ of respondents report the need for team building events, and nearly one-third of them report the need for a more explicit introduction of new employees. Surprising results appear in the domain of events with an integration purpose, in the case of unfortunate events in the lives of employees - although these are present in the respondents' answers below the average, only 5\% report the need for the events in this category.

When it comes to corporate events with learning function, the most common category are corporate seminars in which only some employees participate (eg training sales people), with $61 \%$ in the organizations studied. Education and training in the workplace are more common than those in other locations; together with team-building activities, these are reported to be more desirable and the ones the respondents would like to have more often in their organizations. There is a surprising lack of interest among the respondents for the presentation of new products in the company's assortment. 
Table 3. Corporate events-presence and need for them

\begin{tabular}{|l|l|l|}
\hline Corporate events & Existing & $\begin{array}{l}\text { Preferred, but } \\
\text { non-existingt }\end{array}$ \\
\hline New Year celebrations & $86 \%$ & $0 \%$ \\
\hline $\begin{array}{l}\text { Gatherings on the occasion of important events in the lives of } \\
\text { employees (marriage, child birth, graduation / master / PhD) }\end{array}$ & $61 \%$ & $10 \%$ \\
\hline $\begin{array}{l}\text { Corporate seminars attended by only some employees (eg training } \\
\text { sales people) }\end{array}$ & $61 \%$ & $5 \%$ \\
\hline Celebrating the Day of the company & $46 \%$ & $14 \%$ \\
\hline $\begin{array}{l}\text { Gathering on the occasions of unpleasant (sad / tragic) events in the } \\
\text { lives of employees }\end{array}$ & $46 \%$ & $5 \%$ \\
\hline Education and training in the workplace & $39 \%$ & $38 \%$ \\
\hline $\begin{array}{l}\text { Education and training in other locations (eg. training weekend at } \\
\text { Zlatibor, etc.) }\end{array}$ & $36 \%$ & $43 \%$ \\
\hline Corporate Seminar for Managers & $32 \%$ & $5 \%$ \\
\hline Presentations of new products in the company assortment & $29 \%$ & $0 \%$ \\
\hline $\begin{array}{l}\text { Corporate seminars in which all employees participate (eg, a } \\
\text { seminar on the Day of the company) }\end{array}$ & $21 \%$ & $14 \%$ \\
\hline $\begin{array}{l}\text { Celebrations on the occasion of important events for the company } \\
\text { (eg, winning prizes at fairs, etc.) }\end{array}$ & $18 \%$ & $14 \%$ \\
\hline Introducing new employees / members of the company & $18 \%$ & $29 \%$ \\
\hline The events aimed at team building (team-building activities) & $18 \%$ & $43 \%$ \\
\hline
\end{tabular}

\section{Discussion of the Results}

Empirical research has provided us with the following results:

Result 1: In the structure of corporate events, the events with the aim of integration are dominant over the events with the aim of learning. In the structure of the respondents' needs, the events with learning contents dominate over those with integration contents.

Result 1a: The respondents are extremely dissatisfied with the opportunities to promote their work.

This is especially evident in the case of state-run and public companies as, with the reliability of $90 \%$, we can assess that the respondents employed in these organizations are more dissatisfied with the opportunities for advancement in comparison with other organizations.

When it comes to recognition for a well performed job, the moderating variable is the respondents' marital status, as with $95 \%$ certainty we can say that the married respondents are more dissatisfied with the recognition of a well performed job. When it comes to the relation between the desired and the received award for the work done, the influence of organizational ownership proves to be significant, since with $90 \%$ certainty we can say that the employees in private companies are dissatisfied.

Result 2: Young professionals respect their superiors and colleagues and their competence. What is more, they express a certain emotional reaction - they "love their boss"- "love their colleagues", but still show more interest in the relationship with their superiors than in the relationship with their coworkers.

Result 3: The most important source of job satisfaction for young professionals in Serbia is the job itself the fact that they love their job, enjoy it, are proud of what they do. Inadequate organization is a stronger source of job dissatisfaction among young professionals than their relationships with other people.

Result 4: Incomplete compensation packages are a major source of job dissatisfaction among young professionals in Serbia. Although they are somewhat satisfied with the absolute level of salary and the reputation they enjoy in this sense, the sources of discontent can be found in the prospects for improving their economic position through an increase in salary; short-term perspectives (a raise) and long-term perspectives (an increase in salary) are another source of discontent. In addition to this, the young professionals are not fully aware of what their compensation packages should include (financial, non-financial benefits). 
Gender and education are important individual characteristics that influence the satisfaction with salary. Women are more dissatisfied with the adequacy of the rewards that they receive for their work; based on our research, we can claim this with a $95 \%$ certainty. As for the prospects of an increase in salaries, women are also a more dissatisfied category, which can be claimed with a $90 \%$ certainty. Education level can significantly affect the employees' chances for an increase in salary, since with a $90 \%$ certainty, we can say that the respondents who have finished only graduate studies are more dissatisfied than those with a higher education level (specialization, master, master's degree).

Conslusion

The results of our research show that young professionals in Serbia work a lot, that they are fully involved in the tasks they perform, and that they are proud of their jobs, as well as that their jobs create a feeling of personal satisfaction and fulfillment. The results also show the respondents' positive perception of their superiors' and associates' personal and professional characteristics: they generally respect superiors and co-workers and consider them competent for the work they do. However, the research also shows that corporate events are not exploited enough for the promotion of young professionals, and that they do not provide enough support for the processes of individual and organizational learning, although these motives are among the most important for the population studied.

The sources of dissatisfaction of young professionals in Serbia are mostly present in the areas of job design, communication channels in the organization, promotion and reward systems. Also, the compensation packages for young experts are underdeveloped and leave a lot of space for different motivational strategies.

Our study has certain recommendations for management theory and practice, which will be structured in the form of implications and conclusions - hypotheses for further empirical testing.

Implication 1: Young professionals are the most dissatisfied with the opportunities to promote their work. Conclusion 1: Corporate events are not used enough for the promotion of young professionals, and they do not to support enough the processes of individual and organizational learning.

Implication 2: Young professionals respect their superiors and colleagues and their competences. Moreover, they express a certain emotional reaction - they "love their boss"- "love their colleagues" but, in our study, they show more interest in the relationship with their superiors than that with coworkers. In the relationships with other people, young professionals are more interested in the development, the learning component, than in the social component.

Conclusion 2: When it comes to managing young professionals, the structure of corporate events should be dominated by the events with strong learning rather than those with social potential.

Implication 3: The challenge of the job is the factor that has the greatest motivating potential for the management of job satisfaction among young professionals.

Conclusion 3: When it comes to managing young professionals, the structure of corporate events should be dominated by those that correspond to the improvement of individual skills to do the job, those that enrich, strengthen and increase the employee's ability to perform complicated tasks, and the like.

Implication 4: The amount and the structure of salary alone are not a source of job dissatisfaction among young professionals, it is rather the prospects for the salary increase in the short or in the long run.

Conclusion 4: Corporate events with the purpose of integrating the organization should be used as an opportunity to deliver information to employees on short-term and long-term plans for financial and non-financial rewarding employees.

The results of this study are of interest for both management theory and management practice. Corporate events have been predominantly approached as a marketing management category, and so the effects of these events have mainly been aimed at external public and stakeholders outside the organization.

In this study, we look at corporate events as an organizing tool for managing young professionals, and we state some theoretical implications for managing this particular category of employees. This connection has not been clearly observed or analyzed, and so our research provides a new approach to the existing topics. On the other hand, the results, conclusions and implications that we derive can be of practical use to managers in different areas and on different levels of organizational hierarchy, and especially to experts in the field of human resources, because the research shows that corporate events can be used for a differentiated approach to employees and to managing individual aspects of their behavior in organizations. 


\section{REFERENCES}

[1] Deal, T. E., Kennedy, A. A.. (1982). Corporate Cultures: The Rites and Rituals of Corporate Life, Reading, Mass.: Perseus Books,

[2] Goldblatt, J., Nelson, K., (2001). The International Dictionary of Event Management, Wiley.

[3] Hamori, M., Cao, J., Koyuncu, B., Why Top Young Managers are in the Non Stop Job Hunt, HBR, JulyAugust (2012).

[4] Kostić Stanković, M., Makajić Nikolić, D., Slijepčević M., (2012) Planning of Social Corporate Responsibility Campaign with Multiple Special Event, Management, No59 ISSN 1820-0222

[5] Locke, E.A., (1976). The Nature and Causes of Job Satisfaction. In M.D.Dunnette (ed) Handbook of Industrial and Organizational Psychology (pp.1297-1343). Chicago: Rand and McNally.

[6] London M., Bray, D.W., (1984) Measuring and Developing Young Managers' Career Motivation, Journal of Management Development, Vol. 3 Iss: 3, pp.3 - 25

[7] London, M., (1993) Relationships Between Career Motivation, Empowerment and Support for Career Development, Journal of Occupational and Organizational Psychology, Volume 66, Issue 1, pages 55-69

[8] Robbins, S. (2003) Organizational Behavior, Englewood Cliffs, NJ: Prentice Hall.

[9] Spector, P. E. (1997). Job satisfaction: Application, assessment, causes, and consequences. Thousand Oaks, CA.: Sage.

[10] Smith, P. B.; Peterson, M. F.; Misumi, J., Event management and work team effectiveness in Japan, Britain and USA., Journal of Occupational and Organizational Psychology, Vol 67(1), Mar 1994, 33-43.

[11] Thierry, H., Koopman-Iwema, A.M. (1984) Motivation and satisfaction, in Drenth, P.J.D, Thierry, H., Willems, P.J., and de Wolf, C.J., (eds), Handbook of Industrial and Organizational Psychology, John Willey, Chichester.

[12] Vroom, V.H. (1964), Work and Motivation. San Francisco, CA: Jossey-Bass.

[13] Whitely, W., Dougherty, T.W., Dreher, G.F., (1991) Relationship of Career Mentoring and Socioeconomic Origin to Managers' and Professionals' Early Career Progress, Academy of Management Journal, Vol34. No 2, pp. 331-351.

Receieved: November 2012. Accepted: March 2013.

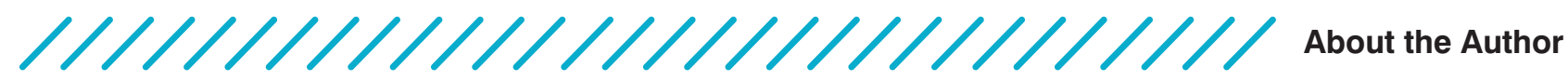

Ana Aleksić-Mirić

University of Belgrade, Faculty of Economics anaa@ekof.bg.ac.rs

Dr Ana Aleksić-Mirić is assistant professor at the Faculty of Economics, University of Belgrade. She holds MSci and PhD degree sfrom the Faculty of Economics, University of Belgrade (PhD in 2009 "Organizational Learning and Knowledge Management in Strategic Alliances: Organizational Design Perspective"). During her PhD education in 2006 she was a visiting scholar at Duke University, Fuqua School of Business (Department of State USA Junior Faculty Development Program). She is skilled in dynamic network analysis and computational organization theory (Carnegie Mellon CASOS certificate in 2008). She served as a World Bank Institute consultant on the project titled Corporate Social Responsibility \& Sustainable Competitiveness in Serbia, and is experienced in consultant activities in the region. Her research interests involve organizational theory, design and behavior within the context of knowledge management and organizational networks and the design of alliances to learn. She is a member of the Scientific Society of Economists of Serbia and of the Organizational Design Community.

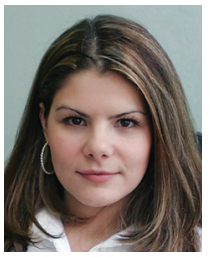

Marina Petrović University of Belgrade, Faculty of Economics marinap@ekof.bg.ac.rs

Marina Petrović graduated in 2005 from the University of Belgrade, Faculty of Economics. Currently she is a PhD student since 2009 at the University of Belgrade, Faculty of Economics. Employed at the Faculty of Economics, University of Belgrade since 2005.Appointed Teaching Assistant in 2009. Main fields of interest and research: Market Research, Statistics.

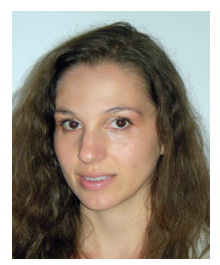
Courses taught on the undergraduate level: Market Research. 